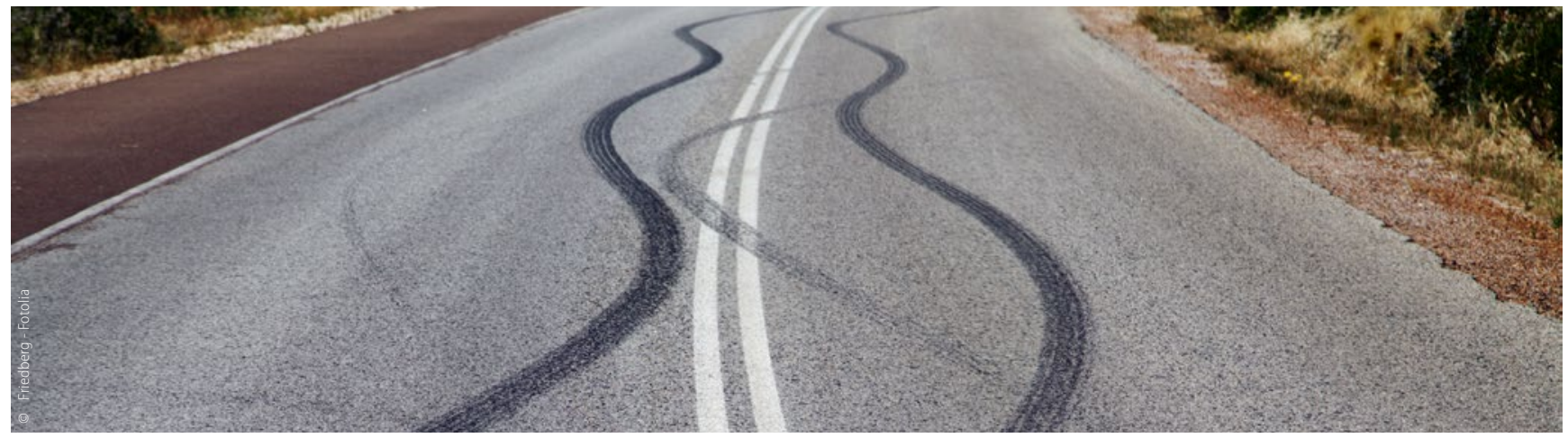

\title{
Gastkommentar
}

\section{Freiheit auf der Verliererstraße?}

\author{
"Wohlstand für alle" - diese Parole gilt in Parteienkreisen als vorteilhaft für Stimmenzuwachs. \\ Unter dieser Etikette versuchen weite politische Kreise, die Macht des Staates Zug um Zug aus- \\ zuweiten. Immer mit der Botschaft: Wir kümmern uns um Euch - auf dass es Euch besser gehe.
}

Besser gehen - das geht aber immer nur auf Kosten anderer. Da korrumpiert man sich in der Politik oft für eine vermeintlich arme Mehrheit in der Bevölkerung und richtet die Neiddebatte gegen diejenigen, die eigentlich das Land mit Kraft und Ideen voranbringen. Wie macht man das? Mehrere Wege werden dafür beschritten.

Ein bereits ausgetretener Weg ist das kontinuierliche Anziehen der Steuerschraube - die ständige Erhöhung der Staatsquote. Sie ist ein Freiheitsverlust für den Steuerbürger. Jede Systemkrise nutzt der Staat zur Argumentation einer außergewöhnlichen Situation, die besondere Lasten erzwingt: Wiedervereinigung, Bankenkrise und Griechenland, demnächst wohl auch die Flüchtlingskrise. Hinzu kommt das schleichende Gift der kalten Progression.

\section{Gerechtigkeit ist nicht relativierbar}

Ein neuer Weg ist der Entzug von Freiheit. Schon die Steuerpolitik wirkt wie ein virtueller Entzug von Freiheit. Der Staat konsumiert immer unverschämter die Bürgerfreiheiten und greift damit die Entfaltungszusage des Grundgesetzes an. Alles unter dem Deckmantel des angeblichen Gemeinwohls und einer angeblichen sozialen Gerechtigkeit. Dabei ist Gerechtigkeit nicht relativierbar - auch nicht als soziale Gerechtigkeit. Oder gibt es etwa prioritäre Bereiche der Gerechtigkeit?

Gerechtigkeit für alle, das bedeutet die Herstellung von Chancengleichheit unter festen Spielregeln.

Die Staatsmacht glaubt aber zunehmend, dem Bürger die Gleichheit aller zu schulden. Im Land läuft eine Nivellierungswelle ohnegleichen. Den Erfolgreichen wird damit zunehmend die Motivation abgeschnitten. Den zukünftig Erfolgreichen wird die Chance genommen, ihr Glück zu machen - und die Freiheit zu scheitern. Auch das ist ein Menschenrecht. Und die Faulen im Staat richten sich ein auf dem frisch bereiteten Staatsbett.

Die Staatsmacht gefährdet die Grundlagen der Freiheit, wenn sie zulässt oder gar fördert, dass Neid und Missgunst zu tragen- den Prinzipien des Zusammenlebens werden. Dabei mahnt schon Schopenhauer, das höchste Lob der Deutschen sei der Verzicht auf Neid. Leider findet der Versuch, Adam Riese durch die Statue des kleinen Milchmädchens zu ersetzen, bei den Volksvertretern immer mehr Befürworter.

\section{Ohne Wettbewerb ermüdet jede Gesellschaft}

Wettbewerb wird zunehmend als ein unsoziales Merkmal in der Gesellschaft gebrandmarkt. Für manche ist es bereits ein kontaminiertes Wort aus dem Neoliberalismus. Aber ohne Wettbewerb ermüdet jede Wirtschaft und jede Gesellschaft. In der Liga der Erfolgreichen, in der Deutschland lange spielte, gibt es allerdings keine Stammplätze.

Freiheit wurde seitens der Machthaber schon immer in Frage gestellt. Wir Bürger müssen sie uns immer wieder erkämpfen. Lassen wir uns dabei nicht vom Odium der Sicherheit betäuben. Sicherheit gibt es nur in Freiheit, es sei denn, man bevorzugt eine Sicherheit im totalitären Sinn.

Halten wir unseren Volksvertretern ihre Defizite in puncto „Gestaltung von Freiheit“ immer wieder vor. Diese Wahrheit ist zwar nicht für jedermann zumutbar, aber sie bleibt deshalb trotzdem real.

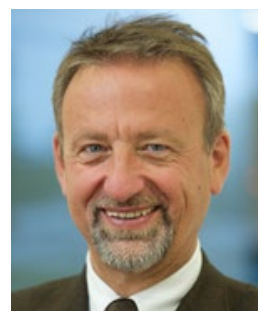

Dr. K. Ulrich Rubehn

Dr. K. Ulrich Rubehn war FVDZ-

Bundesvorstandsmitglied von 2001 bis 2005, danach vier Jahre stv. Bundesvorsitzender und 2009/2013 Präsident der Zahnärztekammer Schleswig-Holstein. 